Manual of Practical Morbid Anatomy. By H. D. Rolleston, M.D., and A. A. Kanthack, M.D. Pp. xix., 240. Cambridge: At the University Press. I894.

It seems rather late in the day to comment upon this useful little book; but as no previous notice of it has appeared in this Journal, we are glad of an opportunity to express our appreciation of its value. Not only is the book a most trustworthy guide to the methods of procedure adopted in the post-mortem room, but most of the morbid conditions seen in diseased organs are referred to and often briefly described. No intelligent student could use this as a hand-book without acquiring a sound basis of knowledge of morbid anatomy. The book displays at of the wide experience of the writers and their appreciation of those leading features that it is necessary to impress upon the beginner.

\title{
Diseases of the Ear, Nose, and Throat, and their Accessory Cavities.
}

By Seth Scott Bishop, M.D. Pp. xv., 496. Philadelphia: The F. A. Davis Company. I897.

It is not uncommon at the present time to meet with textand combining the subjects of ear, nose, and throat diseases, are we have nothing to say against this plan, inasmuch as they pitary closely associated; while in clinical departments of hosthey, where students acquire their knowledge of these subjects, in a very frequently combined. The present work contains affectionserate compass a good condensed account of these exhaustive so as to constitute it a key or introduction to the Severalve treatises which we possess on each topic separately. the ral subjects are treated in greater detail than characterises treatmork as a whole: these being diphtheria, with its antitoxin the treatm ; surgical operations about the mastoid process; and are all in older modern developments, and cannot be found fully treated giving works, hence we think the author has done wisely in excellent them ample space. The chapters on diphtheria are and the A good account is given of the Klebs-Löffler bacillus, organis best means of diagnosing it from other similar microwith isms; while a full account of the treatment by antitoxin, gives its risks as well as its successes, is added. The author mastoid one of the best accounts of the operations about the descriptions process that we have seen in any text-book. His taken tions are very clear, and are illustrated by photographs absolute actly from life or from the cadaver so as to ensure author's accuracy. We are not favourably impressed by the air. with He is not content with the ordinary Politzer's bag, nor with the common method of inflation through the Eustachian 
catheter; but recommends instead the use of a reservoir armed with a pressure gauge, from which compressed air is allowed to issue through a stop-cock and pass through a close-fitting nose-piece into the nasal cavity, with the patient's nose firmly closed and cheeks fully distended. He recommends a pressure varying from a few pounds in infants up to sixty or eighty pounds in old, thickened, and hardened drum-heads. We should be very chary ourselves of using a method such as this, which must admit the possibility of considerable damage being occasionally done; and we altogether fail to see the advantage it possesses over older and safer methods. The book is one which can be safely recommended as a whole, and will amply repay a careful perusal.

Die Färbetechnik des Nervensystems. Von Dr. B. Pollack. Pp. v., I30. Berlin: S. Karger. I897.

This will be found a very valuable little book to those who are working at the pathology of the nervous system. It gives an account of the various methods employed in the preparation of macroscopical and microscopical sections of the brain and spinal cord. As many of these methods are extremely complicated, and the description of some of them has to be hunted out in various journals, it is exceedingly convenient to have them collected together in the handy form of this volume. The author has dealt with his subject in a very complete and satisfactory manner, the description of the various processes being clearly put, and the most recent methods being included. $\mathrm{He}$ presupposes on the part of the reader some general knowledge of the elementary processes used in the cutting and preparing of microscopical sections. The author has compiled a most useful book, which will be found indispensable to all workers at this subject. It forms a volume of convenient size, which is clearly printed, well arranged for reference, with a sufficient index. There are some useful general directions at the end of the book.

An Account of the Life and Works of Dr. Robert Watt. By James Finlayson, M.D. Pp. 46. London: Smith, Elder, \& Co. I897. - The subject of this essay is probably better known to the public and possibly to the medical profession as the author of the Bibliotheca Britannica, than as one of the leading physicians of his time at Glasgow. Dr. Watt, like so many of his countrymen who have distinguished themselves in the world of literature and art, rose from a very humble position chiefly by his own efforts. Beginning life behind the plough, he raised himself to a position of no small reputation as a physician and lecturer on medicine, while from his pen came many useful and thoughtful 